\title{
Standards: Real-time extensions to programming systems
}

\author{
N. JOHN CASTELLAN, JR. \\ Indiana University, Bloomington, Indiana 47401
}

\begin{abstract}
The current status of formal efforts to develop real-time extensions to programming languages like FORTRAN and BASIC are described, and examples of the form of such standards are given. In addition, characteristics of hardware interface standards are presented. Finally, the needs for, and implications of, standards are discussed.
\end{abstract}

In this symposium, three aspects of standards are considered. Dunnagan (1976) considers the problems encountered in making packages of software transportable. Anderson (1976) discusses some alternatives to standards in the evaluation of software packages. My purpose is to discuss the current status of extensions to programming languages for real-time work and some standards for hardware interface.

Out of the shared experience of users of real-time computer systems in research (laboratory automation), industry (process control), and education (CMI/CAI), specific criteria for the functional operation of software in real-time have emerged. As a result of the work of various groups, standards for real-time extensions to common languages like FORTRAN and BASIC have been adopted. In addition. standards for interface design have been proposed, and, in some instances adopted.

One of the first questions that one might ask about standards is: why do we need them? If one looks at the many experimental control languages that have been developed, one is struck with the fact that a tremendous number of man-months have gone into such efforts, and that many have deficiencies which impede their general use and wide acceptance. (See Castellan, 1973, and Wood, Sette, \& Weiss, 1975, for surveys of languages of interest to psychologists.)

One of the problems encountered by psychologists and other behavioral scientists in developing computer-based laboratories is that there is a strong temptation to develop software. There are two reasons for this: (1) With good syntax and grammar, experiments could be designed and programmed in a more natural manner; (2) there is a belief that the available software is unsuitable or inadequate for running experiments in real time. Regardless of how accurate these reasons may have been at one time. the cumulative experience of the last 10 years has shown them to be inappropriate at the present time. With rare exceptions, real-time programming languages developed by psychologists have failed to be implemented beyond their site of development. And because of pressure from a variety of users and the availability of standards, many computer vendors now supply real-time systems that are completely adequate for use in research (Castellan, 1975).

It is the purpose of this paper to outline the organized efforts which have been mounted for the purpose of developing extensions of common languages for real-time operations. In addition, recent efforts directed towards hardware standards will be briefly described.

\section{REAL-TIME LANGUAGE EXTENSIONS}

The two most frequently used languages for real-time process control are FORTRAN and BASIC (Castellan, 1974). There is very little doubt that these languages are also the most frequentiy used ones in laboratory automation.

\section{BASIC}

While BASIC is an extremely popular and widely available language, it does not exist in any standard version. In a study of over 50 different versions of BASIC, Isaacs (Note 1) found that there were large differences between the various "dialects" of BASIC. Recently, ANSI Committee X3J2 accepted a draft standard for a "minimal" BASIC which will probably be approved in the near future. The proposed standard covers only a portion of BASIC and does not include any real-time functions.

A committee under the auspices of the Instrument Society of America (ISA) and other groups [including the International Purdue Workshop on Industrial Computer Systems, the International Federation of Information Processing Societies (IFIPS), and the IEEE] has been attempting to formulate standards for real-time extensions to BASIC (Van Diehl, Note 2). Because there has been no standard version of BASIC, the committee's efforts have been slowed. However, the consensus of the committee seems to be that any extensions should be essentially the same in form and function as the real-time extensions to FORTRAN, which have been under development for a longer period of time. 


\section{FORTRAN}

Although there are many variants of FORTRAN, it does exist in a standard (ANSI) version which most current compilers accept as a base structure upon which to generalize. Extensions to FORTRAN for real-time functions have been developed in a step-wise fashion. The tirst standard was adopted by ISA in 1972 (Note 3) and was recently revised. ${ }^{1}$ This particular standard is known as $\$ 61.1$ and has five features: (1) executive control function, (2) digital input/output, (3) analog input/output, (4) bit-string manipulation, and (5) time-date information.

The goal of the standard is to make comparison of systems easier, make programs more transportable. and improve programming efficiency and accuracy. The standard is organized in such a manner that one can learn quite a bit about the general principles of process control and laboratory automation by a careful reading. The following is an outline of the standard and is not intended to serve as a replacement. For purposes of illustration, the first function category is described in more detail than succeeding categories.

Executive control functions. The purpose of these functions is to direct the execution of programs as a function of time:

\section{CALL START $(i, j, k, m)$ Execute program i after a delay of $j$ counts in terms of time units $\mathrm{k}$.}

\section{CALL TRNON (i,j,m) Execute program $i$, at time of day $\mathrm{j}$.}

\section{CALL WAIT $(\mathrm{j}, \mathrm{k}, \mathrm{m})$ Delay the execution of the current program for time $\mathrm{j}$, in units $\mathrm{k}$.}

In each of the above routines, $m$ is a status flag. The standard specifies the name, function, and parameter sequence of each routine.

Digital input/output. Three functions have been specified: DIW, digital input; DOMW, digital output (momentary or pulse); DOLW, digital output (latching). Like the executive control functions, each routine has a specified set of calling parameters for control and data storage; in the case of the momentary output, the duration is specified.

Analog input/output. As in the case of digital $1 / O$, three functions have been specified: AISQW, analog in put sequential; AIRDW, analog input random; and AOW. analog output.

In the digital and analog $\mathrm{I} / \mathrm{O}$ routines, the order and interpretation of parameters and data arrays are specified by the standard. In addition, it should be noted that each of the six routines has the suffix "W," which specifies that execution of the calling program is to be suspended until the data transfer is complete. When the suffix " $\mathrm{W}$ " is omitted. immediate return to the calling program is required, even though the $I / O$ transfer may be incomplete. While the standard specifies man! important aspects of the I O operation. the timing of the functions and the accuracy (of $A-D$ and $D-A$ conversion) of the routines are not specitied or constrained.

Bit-string manipulation. The standard specities various logical functions (and, or, not. exclusive or), shift functions and routines for testing, setting. and clearing bits.

Time and date functions. These routines enable the user to determine the current time of day and calendar date on-line.

A few of these funtions already exist in some versions of FOR'TRAN. However, w ithout a standard. there would be no unitormity of syntax and function. This problem. "hile seemingly trivial, can lead to serious difficulties. For example, in the timing routines (START, IRNON, and WAIT), the standard is specitic about whether the time period specitied is to be an upper or lower bound on the elapsed time. Such a distinction is important because the hardware clock base may be different from the clock base specitied in the call.

A second standard. S61.2, is in the draft stage. That is. it is being circulated for review and comments prior to acceptance. This standard deals with procedures for handling random unformatted tiles and task management. The tile-handling routines are those $"$ hich deal $w$ ith the creation, deletion, opening. ard closing of files. as well as routines for reading and writing tiles. More controversial are the parts of the standard which deal with task management. These routines deal with the manner in which tasks may be suspended, released, and terminated, as well as the linking of segments. establishing core residence, and the interrogation of status and change of program priorities. The standard also specifies rules for the handling of external tasks (enabling, disabling. and "tree ing." or suspending the external function). Part of the controversy stems from the attempt to make task management and control independent of the operating system.

\section{HARDWARE INTERFACES}

Because of the proliferation of a large number of different computers and the even larger number of ways to interface devices to computers, there have been several attempts to define standards for interfaces. There have been two major efforts at specifying standards. one centered in Europe and the other in the United States. The European effort is known as CAMAC, and the more recent American effort is know $n$ as the IEEE Standard.

\section{CAMAC}

CAMAC was detined originally by the ESONE 
committee, a multinational organization of computer users at nuclear installations. However, as the standard developed, it became clear that it dealt with data-handling tasks which were far more general in scope and application-including process control and laboratory automation. While the standard includes both hardware and software, primary emphasis has been on the former.

CAMAC consists of the designation of rules for the design and use of modular electronic data-handling equipment. These rules offer a standard procedure for the interfacing of data transducers and actuators to computer in on-line systems. The purpose of the standard is to encourage common procedures and compatability between hardware and software from different sources and used in diverse application areas.

The European CAMAC Association is a group of users and manufacturers concerned with dissemination of the standard and evaluation of further aspects of measurement and control systems. The association publishes a journal three times a year (e.g., Meyer, Note 4) and organizes an international symposium each year.

The various aspects of the CAMAC standard (or system) are elegant, general, and systemindependent. However, while both software and hardware conforming to the CAMAC standard are available in the United States, the system is relatively expensive to implement and, to some extent, does not take advantage of recent advances in electronics design.

\section{The IEEE Standard}

In December 1974, the IEEE adopted a "Standard Digital Interface for Programmable Instrumentation" (IEEE, Note 5). Whereas the CAMAC standard covers digital and analog $\mathrm{I} / \mathrm{O}$, and hardware as well as software, the IEEE standard is more modest, but perhaps more successful within its limited scope. ${ }^{2}$ The scope of the standard is limited as follows: (1) It deals only with digital data exchanged among the interconnected apparatus (as opposed to analog data transfer); (2) The number of devices which may be interconnected by one contiguous bus may not exceed 15; (3) The total transmission path length overall all interconnecting cables may not exceed $20 \mathrm{~m}$; (4) The data rate across the interface on any signal line may not exceed $1 \mathrm{Mb} / \mathrm{sec}$. While there may be many digital I/O tasks which do not meet the above criteria, such tasks do not come within the purview of the standard. In addition, the standard deals only with the interface characteristics of the instrumentcomputer system and not with the design specifications, performance requirements, and safety features of the apparatus. The standard is intended to apply to interface systems used to interconnect both programmable and nonprogrammable electronic measuring components with other components and apparatus necessary to assemble instrumentation or control systems. The standard may also be relevant and apply to system components such as processors, display devices, storage devices, or terminal devices which form part of instrumentation systems.

The overall purpose of the interface is to provide a communication link over which "messages" may be carried in an unambiguous way among a group of interconnected devices. The messages may be of two general types. The first type is used to manage the interface system itself. These care called "interface messages" or control messages. The second type is used by the device but not by the interface. These are called device-dependent messages or data.

The device is conceptualized in terms of its function, as a listener, a talker, or a controller. A listener is a device that can receive information, a talker is a device that can send messages to another device, and a controller can tell (address) other devices to listen or talk. In addition, it can send messages to direct actions within other devices.

The message path of the bus structure consists of 16 signal lines divided into three functionally different sets. The first set is the data bus which consists of eight asynchronous, bidirectional, bit-parallel, byte serial signal lines. The second set consists of three lines that describe the status of data handling - data valid, not ready for data, and data accepted. These lines are used to transfer the data across the interface. The third set of lines are the management lines and are used as attention, interface clear, service request, enable, and end-of-data signals. Thus, these are the control lines.

The IEEE interface is being implemented rapidly by many mainframe and peripheral manufacturers. As the standard becomes more widely adopted, it will serve to make the interfacing of digital services more efficient. transportable, and less costly. The potential for intersubstitutability of devices is only beginning to be realized.

\section{SUMMARY}

Over the past several years, many psychologists were diverted from their primary research goals to the design of hardware and software systems. This may have been necessary in some cases. However, as the computer industry becomes more carefully tuned to the needs of researchers. such technical work will become less critical to the maintenance of an active research laboratory. The extent (and cost) of this freedom to return to research will depend in large measure upon the adoption of suitable standards for hardware and software.

While some laboratories will continue to provide joint training and research in computer science, it will 
not be necessary for all laboratories to be so engaged. There is an interesting parallel in the use of statistical software packages. At one time, anyone wanting to do an analysis of variance or correlational study wrote his or her own program. We no longer need to write our own software except when such work is part of training in psychometrics. Rather, we use one of the many statistical packages available. There is no standard for the statistical packages that we have been using for years. Only recently has an effort been made to establish standards for such packages (Francis, Heiberger, \& Velleman, 1975). In some of these packages, major errors have gone unnoticed (or uncorrected) for years.

It is important that psychologists who use laboratory computers keep informed about the development of standards. If informed, researchers will be in a strong position to influence and hasten the development and adoption of standards, and, if successful, we shall be able to focus our attention on conducting productive research rather than trying to get the apparatus built.

\section{REFERENCE NOTES}

1. Isaacs. Gerald L. Interdialect translatability of the BASIC programming language. Iowa City: American College Testing Program. Techncal Bulletin No. 11, 1973.

2. Van Diehl, W. Functional needs for real-time enhancements to minimal BASIC. In Proceedings. Second Annual Meeting. International Purdue Workshop on Industrial Computer Systems. Part I, 1974, 197-205.

3. Instrument Society of America. Stundard Industrial computer system Fortran procedures for executive functions and process input-output (ISA-S61.1). Pittsburgh: Author, 1972.
4. Mever, H. (Editorial Chamman) CAMAC Bulletm Geel (Belgutu): CBNM EURATOM. 14า5.

5. Institute of Electrical and Electronics Engineers. IEEE Standard Digital Interface for Programmable Instrumentation. (IFFE Sid 488-1975). New York. Author, 1975.

\section{REFERENCES}

Anderson. R. E. Techmcal stindards and pertormance standards in the pursuit of quality. Behavior Research Methods \& Instrumentation. 1976, 8. 211-217.

Castellan, N. J.. JR. Laborators programming languages and standardization. Behawor Research Methods a Instriminua I10n, 1973, 5, 249.252

Castellan, N. J., JR. Survey questionnatic on priciss languages. In Proceedings. 1974 Spring Kegtomal Mletimg of Intermutional Purdue Workshop on Industrial (istitrol Languages. April 1974. Pp. 131138.

Castellan. N. J . JR. The modern mumcomputer in laborator automation. American Psychologist, 1975. 30. 205-211.

DLnnagan. T. CONDLit standards and procedures: A practical experience. Behavior Research Methods \& Instrumentation, 1976, 8. 205-206.

Francis. I.. Heiberger, R. M.. d Velleman. P F. Criteria and consideratoms in the evaluation of statistical program packages. American Statusticun, 1975, 29. 5256

Wood. R. W.. Sette, W. F.. \& Weiss, B. Interfacing the experimenter to the computer: Languages for psychologists American Psychologist, 1975, 30, 230-238.

\section{NOTES}

1. Further information on this standard may be obtaned from the Standards and Practices Board Secretart. Instrument Society of Anereat. 400 Stammix Strect. Pittsburgh. Pennswlsama 15222.

2 Further intormation on this standard may be obtaned from the ILEF Siandards Board. Institute of Electrical and Electrones Engineers. Inc., 345 East 47th Street, New York. New York 1001?7 